\title{
Evaluation of HACCP Plans of Food Industries: Case Study Conducted by the Servizio di Igiene degli Alimenti e della Nutrizione (Food and Nutrition Health Service) of the Local Health Authority of Foggia, Italy
}

\author{
Michele F. Panunzio ${ }^{1 *}$, Antonietta Antoniciello ${ }^{1}$, Alessandra Pisano ${ }^{1}$, and Giovanna Rosa ${ }^{2}$ \\ ${ }^{1}$ Food and Nutrition Health Services, Local Health Authority, Foggia, Italy \\ ${ }^{2}$ Health Department of Puglia Region, Italy \\ *Correspondence to Dr. Michele F. Panunzio; E-mail: mpanunz@tiscali.it
}

Received: 04 September 2007 / Accepted: 22 September 2007 / Published: 30 September 2007

\begin{abstract}
With respect to food safety, many works have studied the effectiveness of self-monitoring plans of food companies, designed using the Hazard Analysis and Critical Control Point (HACCP) method. On the other hand, indepth research has not been made concerning the adherence of the plans to HACCP standards. During our research, we evaluated 116 self-monitoring plans adopted by food companies located in the territory of the Local Health Authority (LHA) of Foggia, Italy. The general errors (terminology, philosophy and redundancy) and the specific errors (transversal plan, critical limits, hazard specificity, and lack of procedures) were standardized. Concerning the general errors, terminological errors pertain to half the plans examined, $47 \%$ include superfluous elements and $60 \%$ have repetitive subjects. With regards to the specific errors, $77 \%$ of the plans examined contained specific errors. The evaluation has pointed out the lack of comprehension of the HACCP system by the food companies and has allowed the Servizio di Igiene degli Alimenti e della Nutrizione (Food and Nutrition Health Service), in its capacity as a control body, to intervene with the companies in order to improve designing HACCP plans.
\end{abstract}

\section{Introduction}

Over the past years in Italy, the current affairs press has produced ample information on the subject of HACCP (Hazard Analysis and Critical Control Points) with the goal of providing support to those in charge of food companies and to allow these companies to conform to that provided for by Italian Legislative Decree no.155/97, which introduced the self-monitoring system. Numerous training courses for public and private bodies were organized with the same goal. After an initial HACCP system planning period, marked on the legislative level by the different derogations to the sanctions, we have now reached complete actuation of self-monitoring. During this phase, the evaluation of selfmonitoring plans plays an important role, as it is an important activity for interlocution between the person in charge of the food industry and the health authority.

The evaluation investigates the concreteness of the self-monitoring plans with reference to the hygienicsanitary safety of foods [1]. Food companies essentially - in addition to having "the piece of paper" of the selfmonitoring plan (and in many cases, they are substantial, well laid out volumes with various colours) - must adopt all the procedures indicated in the plans themselves in order to knock down or reduce potential hazards [2-5].

Panunzio et al. [6] introduced and used an evaluation sheet that took into consideration the most important aspects of self-monitoring from the point of view of specificity, simplicity, feasibility and adherence. In this manner, different self-monitoring plans were evaluated using these four profiles; a score was determined and for each profile. The question we asked ourselves during the study of this work was what evaluation of the selfmonitoring plans can be made in the light of adherence to the HACCP method?

Adherence was taken into consideration because it is the most critical aspect of the self-monitoring plans that contain HACCP principles. When a plan is drawn up based on photocopies of other non-specific plans, the HACCP method is generally almost non-existent because it was not based on the individual company [7-10]. 
Therefore, we evaluated a sample of self-monitoring plans drawn up by just as many food companies located in the LHA territory of Foggia.

\section{Materials and Methods}

During the period from January-December 2006, 116 self-monitoring plans were taken under examination and evaluated, which had been drawn up by food companies whose production, distribution and/or sales offices were located within the territorial area of the LHA of Foggia. Using randomization and the technique of layered sampling, we proceeded with identifying the food companies. The sample extracted in this manner, even if not representational, can supply a measure of the most common methodological mistakes.

The evaluation aspects focused their attention on adherence to the HACCP method, as it was felt to be the main measure of credibility for a self-monitoring plan self-monitoring that explicitly refers to this method. Metaphorically, adherence is the "neck of a bottle" that contains specificity, simplicity and feasibility of HACCP plans. Therefore, beginning with the evaluation sheet, errors were classified as general and specific while the plans were divided into classes of activities of the food companies, as indicated in enclosure no. 1 of Italian Ministerial Decree no. 185 dated October $16^{\text {th }}, 1998$.

Table 1 indicates the distribution of the companies per activity class, whose self-monitoring plans were evaluated. Based on the evidence of the application of the evaluation sheet, the errors were classified as general and specific. The general errors were linked with three types: terminology, voluminosity and redundancy.

Table 1: Food companies examined, for classes of activity.

\begin{tabular}{lcr} 
Classes of activity & Number & $\%$ \\
\hline Food industry & 18 & 15.52 \\
Wholesale trade & 16 & 13.79 \\
Retail trade & 44 & 37.93 \\
Hotel, restaurant and cafeteria & 33 & 28.45 \\
Work canteen & 5 & 4.31 \\
\hline Total & 116 & 100.00 \\
\hline
\end{tabular}

Concerning terminology, a very frequent error was that of using the name "self-monitoring manual" for what was the "self-monitoring plan" thus confusing a nonspecific instrument such as the manual, which can be written by public and private bodies - whose effectiveness depends on the validation of the same by the Ministry for Health - and which can be of support only in the identification phase of potential hazards and procedures of correct hygienic practice.

Voluminosity refers to the voluminosity of the selfmonitoring plans; it would almost seem that the "validity" of the plans is directly proportional to their paper weight. Well-packaged self-monitoring plans were examined with good typographical layout and coloured sheets, but that were filled with superfluous elements such as the legislation, philosophy and the history of HACCP. These elements invalidated rapid consultation of the plan, making the plan lack in the inspiring motto "only write what you have to do, do what you have written".

Concerning redundancy, a few plans did not follow a precise table of contents for their subjects but rather many things were repeated in different parts of the plan. This resulted in rather difficult specific, immediate and unambiguous comprehension of the procedures to be followed.

The specific errors refer to: the plan for transversal phases, confusion of critical limits, hazard non-specificity and lack of a time plan for the control.

In the self-monitoring plans for transversal phases, the sheets were not drawn up following the production flow chart but rather by homogeneous phases of the production process. This way for example, instead of a few sales businesses having a plan concerning frozen products that included the receiving, storing and sales phases, a plan for the receiving phase, one for the storing phase and finally one for the sales phase were designed for all food products for sale. In this manner, the application of the decision tree in identifying the CCP was ignored. The decision tree is a diagram indicating a few questions/answers, built on the flow of the production activity. Its use is an essential tool to remove the inherent subjectivity in self-monitoring.

Non-specificity of the hazard refers to the generic wording such a biological, physical or chemical contamination. If the hazard is non-specific, it goes without saying that the rest of the plan can only be generic and therefore useless.

Finally, a few plans did not indicate a time plan for the controls to carry out, therefore there was no precise agenda to follow for hazard self-monitoring measures.

\section{Results}

During the period January-December 2006, the Servizio di Igiene degli Alimenti e della Nutrizione (Food and Nutrition Health Service) of LHA evaluated 116 HACCP plans of food companies.

Table 2 takes into consideration the presence or lack of general errors. As can be seen, almost two-thirds of the plans examined contained general errors. The most interesting are: hotels, restaurants and coffee bars in $85 \%$ of the cases against one-third of the food industries. 
Table 2: Presence of general errors in the level HACCP, for class of activity of the firms.

\begin{tabular}{|c|c|c|c|c|c|c|c|c|c|c|c|c|}
\hline \multirow{2}{*}{ General errors } & \multicolumn{2}{|c|}{ Food industry } & \multicolumn{2}{|c|}{$\begin{array}{c}\text { Wholesale } \\
\text { trade }\end{array}$} & \multicolumn{2}{|c|}{ Retail trade } & \multicolumn{2}{|c|}{$\begin{array}{c}\text { Hotels restaurant } \\
\text { and cafeteria }\end{array}$} & \multicolumn{2}{|c|}{ Work canteen } & \multicolumn{2}{|c|}{ Total } \\
\hline & No. & $\%$ & No. & $\%$ & No. & $\%$ & No. & $\%$ & No. & $\%$ & No. & $\%$ \\
\hline Absence of general errors & 12 & 66.67 & 4 & 25.00 & 11 & 25.00 & 5 & 15.15 & 2 & 40.00 & 34 & 29.31 \\
\hline Presence of general errors & 6 & 33.33 & 12 & 75.00 & 33 & 75.00 & 28 & 84.85 & 3 & 60.00 & 82 & 70.69 \\
\hline Total & 18 & 100.00 & 16 & 100.00 & 44 & 100.00 & 33 & 100.00 & 5 & 100.00 & 116 & 100.00 \\
\hline
\end{tabular}

Table 3: Distribution of the general errors, for class of activity of the firms.

\begin{tabular}{|c|c|c|c|c|c|c|c|c|c|c|c|c|}
\hline \multirow[t]{2}{*}{ General errors } & \multicolumn{2}{|c|}{ Food industry } & \multicolumn{2}{|c|}{$\begin{array}{c}\text { Wholesale } \\
\text { trade }\end{array}$} & \multicolumn{2}{|c|}{ Retail trade } & \multicolumn{2}{|c|}{$\begin{array}{c}\text { Hotels restaurant } \\
\text { and cafeteria }\end{array}$} & \multicolumn{2}{|c|}{ Work canteen } & \multicolumn{2}{|c|}{ Total } \\
\hline & No. & $\%$ & No. & $\%$ & No. & $\%$ & No. & $\%$ & No. & $\%$ & No. & $\%$ \\
\hline Terminology & 2 & 4 & 5 & 10 & 23 & 44 & 20 & 38 & 2 & 4 & 52 & 100 \\
\hline Philosophy & 3 & 6 & 9 & 19 & 15 & 32 & 17 & 36 & 3 & 6 & 47 & 100 \\
\hline Redundancy & 5 & 8 & 7 & 12 & 30 & 50 & 15 & 25 & 3 & 5 & 60 & 100 \\
\hline Total & 10 & 6 & 21 & 13 & 68 & 43 & 52 & 33 & 8 & 5 & 159 & 100 \\
\hline
\end{tabular}

Table 4: Distribution of the general errors, for class of activity of the food companies.

\begin{tabular}{|c|c|c|c|c|c|c|c|c|c|c|c|c|}
\hline \multirow{2}{*}{ General errors } & \multicolumn{2}{|c|}{ Food industry } & \multicolumn{2}{|c|}{$\begin{array}{l}\text { Wholesale } \\
\text { trade }\end{array}$} & \multicolumn{2}{|c|}{ Retail trade } & \multicolumn{2}{|c|}{$\begin{array}{c}\text { Hotels restaurant } \\
\text { and cafeteria }\end{array}$} & \multicolumn{2}{|c|}{ Work canteen } & \multicolumn{2}{|c|}{ Total } \\
\hline & No. & $\begin{array}{c}\% \\
(N=6)\end{array}$ & No. & $\begin{array}{c}\% \\
(N=12)\end{array}$ & No. & $\begin{array}{c}\% \\
(N=33)\end{array}$ & No. & $\begin{array}{c}\% \\
(N=28)\end{array}$ & No. & $\begin{array}{c}\% \\
(N=3)\end{array}$ & No. & $\begin{array}{c}\% \\
(N=82)\end{array}$ \\
\hline Terminology & 2 & 33 & 5 & 42 & 23 & 70 & 20 & 71 & 2 & 67 & 52 & 63 \\
\hline Philosophy & 3 & 50 & 9 & 75 & 15 & 45 & 17 & 61 & 3 & 100 & 47 & 57 \\
\hline Redundancy & 5 & 83 & 7 & 58 & 30 & 91 & 15 & 54 & 3 & 100 & 60 & 73 \\
\hline
\end{tabular}

Table 5: Presence of specific errors in the level HACCP, for class of activity of the food companies.

\begin{tabular}{|c|c|c|c|c|c|c|c|c|c|c|c|c|}
\hline \multirow[t]{2}{*}{ Specific errors } & \multicolumn{2}{|c|}{ Food industry } & \multicolumn{2}{|c|}{$\begin{array}{l}\text { Wholesale } \\
\text { trade }\end{array}$} & \multicolumn{2}{|c|}{ Retail trade } & \multicolumn{2}{|c|}{$\begin{array}{c}\text { Hotels restaurant } \\
\text { and cafeteria }\end{array}$} & \multicolumn{2}{|c|}{ Work canteen } & \multicolumn{2}{|c|}{ Total } \\
\hline & No. & $\%$ & No. & $\%$ & No. & $\%$ & No. & $\%$ & No. & $\%$ & No. & $\%$ \\
\hline Absence of specific errors & 15 & 83 & 3 & 19 & 13 & 30 & 6 & 18 & 1 & 20 & 38 & 33 \\
\hline Presence of specific errors & 3 & 17 & 13 & 81 & 31 & 70 & 27 & 82 & 4 & 80 & 78 & 67 \\
\hline Total & 18 & 100 & 16 & 100 & 44 & 100 & 33 & 100 & 5 & 100 & 116 & 100 \\
\hline
\end{tabular}

Table 6: Distribution of the general errors, for class of activity of the food companies.

\begin{tabular}{|c|c|c|c|c|c|c|c|c|c|c|c|c|}
\hline \multirow[t]{2}{*}{ Specific errors } & \multicolumn{2}{|c|}{ Food industry } & \multicolumn{2}{|c|}{$\begin{array}{c}\text { Wholesale } \\
\text { trade }\end{array}$} & \multicolumn{2}{|c|}{ Retail trade } & \multicolumn{2}{|c|}{$\begin{array}{c}\text { Hotels restaurant } \\
\text { and cafeteria }\end{array}$} & \multicolumn{2}{|c|}{ Work canteen } & \multicolumn{2}{|c|}{ Total } \\
\hline & No. & $\%$ & No. & $\%$ & No. & $\%$ & No. & $\%$ & No. & $\%$ & No. & $\%$ \\
\hline Transversal plan & 0 & 0 & 8 & 13 & 28 & 44 & 25 & 39 & 3 & 5 & 64 & 100 \\
\hline Critical limits & 3 & 4 & 12 & 18 & 30 & 44 & 21 & 31 & 2 & 3 & 68 & 100 \\
\hline Specificity of the risk & 0 & 0 & 11 & 18 & 22 & 37 & 23 & 38 & 4 & 7 & 60 & 100 \\
\hline Absence of procedures & 0 & 0 & 7 & 18 & 14 & 36 & 16 & 41 & 2 & 5 & 39 & 100 \\
\hline Total & 3 & 1 & 38 & 16 & 94 & 41 & 85 & 37 & 11 & 5 & 231 & 100 \\
\hline
\end{tabular}


Table 7: Distribution of the general errors, for class of activity of the food companies.

\begin{tabular}{|c|c|c|c|c|c|c|c|c|c|c|c|c|}
\hline \multirow{2}{*}{ Specific errors } & \multicolumn{2}{|c|}{ Food industry } & \multicolumn{2}{|c|}{$\begin{array}{l}\text { Wholesale } \\
\text { trade }\end{array}$} & \multicolumn{2}{|c|}{ Retail trade } & \multicolumn{2}{|c|}{$\begin{array}{c}\text { Hotels restaurant } \\
\text { and cafeteria }\end{array}$} & \multicolumn{2}{|c|}{ Work canteen } & \multicolumn{2}{|c|}{ Total } \\
\hline & No. & $\begin{array}{c}\% \\
N=3\end{array}$ & No. & $\begin{array}{c}\% \\
N=13\end{array}$ & No. & $\begin{array}{c}\% \\
N=31\end{array}$ & No. & $\begin{array}{c}\% \\
N=27 \\
\end{array}$ & No. & $\begin{array}{c}\% \\
N=4\end{array}$ & No. & $\begin{array}{c}\% \\
N=78\end{array}$ \\
\hline Transversal plan & 0 & 0 & 8 & 62 & 28 & 90 & 25 & 93 & 3 & 75 & 64 & 82 \\
\hline Critical limits & 3 & 100 & 12 & 92 & 30 & 97 & 21 & 78 & 2 & 50 & 68 & 87 \\
\hline Specificity of the risk & 0 & 0 & 11 & 85 & 22 & 71 & 23 & 85 & 4 & 100 & 60 & 77 \\
\hline Absence of procedures & 0 & 0 & 7 & 54 & 14 & 45 & 16 & 59 & 2 & 50 & 39 & 50 \\
\hline
\end{tabular}

Table 8: Performance general errors and specific errors.

\begin{tabular}{lccccc}
\hline Performance & Food industry & Wholesale trade & Retail trade & $\begin{array}{c}\text { Hotels restaurant and } \\
\text { cafeteria }\end{array}$ & $\begin{array}{c}\text { Work } \\
\text { canteen }\end{array}$ \\
\hline General errors & 2.12629 & 5.4387 & 1.9773 & 2.98770 & 13.92111 \\
Specific errors & 1.0954 & 5.8738 & 1.8455 & 2.88225 & 18.56148 \\
\hline
\end{tabular}

Table 3 examines the general errors by activity class of the companies. Terminological errors involve half of the HACCP plans containing general errors and $47 \%$ involve superfluous elements, while $60 \%$ of the cases include subject redundancy. The three types of errors mainly involve retail trade.

Table 4 indicates the percentages of each type of general error based on the number of plans that contained these errors. Subject redundancy is the general error that HACCP plans contained the most of for all activity classes of food companies. With the exception of terminology errors in the food and beverage class, all other errors exceed $50 \%$ frequency in the other activity classes.

Specific errors are examined beginning with Table 5. These errors mainly involve retail trade, food industry and wholesale trade.

Table 6 indicates the frequency of the specific errors in relation to corporate activity classes. The lack of procedures is the least frequent error, while the other three types of errors involve the different activity areas in a different manner. The area containing the most specific errors, in the four types considered, in HACCP plans, is that of retail trade, hotels, restaurants and coffee bars. The most frequent specific errors are the transversal plan and the critical limits, both concerning the retail trade area.

In Table 7, specific errors are layered on the frequency of the HACCP plans that contain errors. Frequencies are high for all types of errors and for the different activity classes, except for the food and beverage industry, where there are only three HACCP plans containing specific errors, which all involved erroneous critical limits. In the same manner, the non- specificity of the hazard involved all incorrect HACCP plans in the canteen area.

Table 8 illustrates the performance relative to the general and specific errors per corporate activity class. Performance is obtained from the relation between the error percentage and the percentage of the corporate industry taken into consideration. The emerging results indicate that the canteen area obtained the worst score (13.92 in general error performance; 18.561 in specific error performance), followed by wholesale businesses and business intermediaries (the two performances respectively: 5.44 and 5.87) and then at a distance, the other areas were distributed on the same level.

\section{Discussion}

The goal of this work is to examine the errors contained in the self-monitoring plans of the food industry that are modelled on the HACCP method, in compliance with Italian Leg. Decree no. 155/97. Even if the sample examined is not representational of the entire universe of food companies present in the territory of the LHA of Foggia, it can nevertheless be considered a preliminary study concerning the evaluation of methodological and formal errors of HACCP plans.

An analysis of the results does not indicate a reassuring picture of self-monitoring. In our opinion, the error with the most significance is the non-specificity of the plans that involve all activity classes, with the exception of the food and beverage industry. Even if it is difficult to be able to attribute the meaning of this last data to a sampling fault or to a specific reality, the high frequency of the non-specificity of the hazard, if confirmed by further studies, could nevertheless indicate a passive acceptance of the contents of Italian Legislative Decree no. $155 / 97$ by food companies who have obviously understood formally conforming to the law as the adoption of a self-monitoring plan, but who have not taken enough interest concerning the possibility of using this tool to improve the hygienic-sanitary safety of foods. Although it is a theory still to be proven by facts, negative feedback might be given. 
Therefore, an important role is taken on by those professionals who, in their capacity as true and proper food company trainers, are involved throughout the different phases of making adjustments to and managing self-monitoring [11-12]. If the output of the selfmonitoring system is the recording of procedures and selfmonitoring plans, the outcome of HACCP is the healthiness of food [13].

In our capacity as a public control body, we are interested in both; however, the greatest attention is paid to outcome in order to guarantee the healthiness of foods. The evaluation of HACCP plans concerning methodological errors can constitute a method of dealing with the output while not losing sight of the final goal of safeguarding the consumer [14-16].

\section{References}

1. Olson, K. E.; Slack, G. N: Food safety begins on the farm: the viewpoint of the producer. Rev Sci Tech. 2006, 25(2): 529-539.

2. MacDonald, D. J.: HACCP lessons. $J$ Environ Health, 2002, 64(6): 26-28.

3. Worsfold, D: A survey of food safety training in small food manufacturers. Int $J$ Environ Health Res. 2005, 15(4):281-288.

4. Huggett, A. C: Risk management-an industry approach. Biomed Environ Sci. 2001, 14(1-2):21-29.

5. McMeekin, T. A.; Baranyi, J.; Bowman, J.; Dalgaard, P.; Kirk, M.; Ross, T.; Schmid, S.; Zwietering, M. H: Information systems in food safety management. Int J Food Microbiol., 2006, 112(3): 181-194.

6. Panunzio, M. F.; Antoniciello, A.; Pisano, A: System of index and indicators for the quality evaluation of HACCP plans based on the results of the official controls conducted by the Servizio di Igiene degli Alimenti e della Nutrizione (Food and Nutrition Health Service) of the Local Health Authority of Foggia, Italy. Int. J. Environ Health Res. 2007, 4(1), 34-38.

7. Glavin, M. O.: HACCP: we've only just begun. Food Drug Law J. 2001, 56(2): 137-142.

8. Herrera, A. G.: The hazard analysis and critical control point system in food safety. Methods $\mathrm{Mol}$ Biol. 2004, 268: 235-280.

9. Abernathy, T.; Hart R.: Evaluation of a HACCP pilot program for the food service industry. Can J Public Health, 2004, 95(6): 470-472.

10. Aruoma, O. I.: The impact of food regulation on the food supply chain. Toxicology, 2006, 221(1): 119127.

11. Biondi, A.; Antonini, A.; Pasca-Raymondo, F.; Tarsitani, G.: The HACCP method for personnel education. Ann Ig. 2006, 18(1): 31-39.

12. Huggett, A. C.: Risk management-an industry approach. Biomed Environ Sci, 2001, 14(1-2):21-29.

13. Hulebak, K. L.; Schlosser, W.: Hazard analysis and critical control point (HACCP) history and conceptual overview. Risk Anal. 2002, 22(3): 547-552.

14. Stecchini, M. L.; Del Torre, M.: The food safety management system. Vet Res Commun. 2005, 29 (2): 117-121.

15. Worsfold, D.; Worsfold, P.: Increasing HACCP awareness: a training intervention for caterers. $J R$ Soc Health, 2005, 125 (3):129-135.

16. van der Spiegel, M.; Luning, P. A.; Ziggers, G. W.; Jongen, W. M.: Evaluation of performance measurement instruments on their use for food quality systems. Crit. Rev. Food Sci. Nutr., 2004, 44 (7-8): 501-512. 